\title{
Differentiation of Yin, Yang and Stasis Syndromes in Severe Aplastic Anemia Patients Undergoing Allogeneic Hematopoietic Stem Cell Transplantation and Their Correlation with Iron Metabolism, cAMP/ cGMP, I7-OH-CS and Thyroxine
}

\author{
Huijin $\mathrm{Hu}^{1}{ }^{\prime} *$ \\ Tao Chen ${ }^{2, *}$ \\ Wenbin Liu' \\ Yiping Shen' \\ Qiushuang Li (iD) ${ }^{3}$ \\ Yuhong Zhou' \\ Baodong $\mathrm{Ye}$ (D) \\ Dijiong $\mathrm{Wu} \mathbb{D}^{\prime}$
}

\begin{abstract}
'Department of Hematology, The First Affiliated Hospital of Zhejiang Chinese Medical University, Hangzhou, Zhejiang, People's Republic of China; ${ }^{2}$ Department of Hematology, Xiaoshan Traditional Chinese Medical Hospital, Hangzhou, Zhejiang, People's Republic of China; ${ }^{3}$ Center of Clinical Evaluation and Analysis, The First Affiliated Hospital of Zhejiang Chinese Medical University, Hangzhou, Zhejiang, People's Republic of China
\end{abstract}

*These authors contributed equally to this work

Correspondence: Dijiong Wu; Baodong Ye Department of Hematology, The First Affiliated Hospital of Zhejiang Chinese Medical University, \#54 Youdian Road, Hangzhou, Zhejiang, 3 I0006, People's Republic of China

Fax +8657I87073569

Email wudijiong@zcmu.edu.cn;

I358845350I@I63.com

\begin{abstract}
Objective: To better understanding and differentiation of traditional Chinese medicine (TCM) syndromes in severe aplastic anemia (SAA) patients undergoing hematopoietic stem cell transplantation (Allo-HSCT) and their correlation with iron metabolism, cAMP/ cGMP, 17-OH-CS and thyroxine.
\end{abstract}

Methods: Eighteen patients with SAA who underwent HSCT were enrolled. The syndrome was evaluated before conditioning and days after stem cell reinfusion $(-10 \mathrm{~d},-1 \mathrm{~d},+7 \mathrm{~d},+30 \mathrm{~d}$, $+60 \mathrm{~d}$, and $+90 \mathrm{~d}$ ). The correlation of TCM syndrome (Yin, Yang, and stasis) to cyclic nucleotides, 17-OH-CS, thyroxine, and iron metabolism were analyzed and compared to data from normal subjects.

Results: More "Yin deficiency" ( $\mathrm{n}=11,11 / 18)$ syndrome was observed before HSCT, and nearly $61 \%$ was complicated with "blood stasis". After conditioning, the proportion of "kidney Yin and Yang deficiency" increased to $61.6 \%$. Fourteen days after HSCT, the syndrome developed into "Spleen-Kidney Yang Deficiency," and the stasis score decreased. On +90day, majority patients were diagnosed with "Kidney Yang Deficiency" (35.7\%) or "Spleen-Kidney Yang Deficiency" (28.6\%), and $88.9 \%$ were diagnosed without stasis. The correlation analysis showed that cGMP might represent "Deficient Yang" as well as low total triiodothyronine (T3) and free T3 (FT3). There was also a positive relation between labile plasma iron (LPI), hepcidin, soluble transferrin receptor (sTfR), and "Yin deficiency", and the last two factors, along with marrow nitric oxide synthase were also positively related to "Stasis" syndrome.

Conclusion: During HSCT, the syndrome evolved from "kidney Yin and Yang deficiency" to "kidney Yang deficiency" or "spleen-kidney Yang deficiency", and the "stasis" along with "Yin deficiency" syndromes were quickly relieved within 90 days. The changes of cyclic nucleotides, 17-OH-CS, thyroxine, and iron metabolism indexes can be applied for better differentiation of TCM syndrome.

Keywords: aplastic anemia, traditional Chinese medicine syndrome, iron metabolism, syndrome evolution, hematopoietic stem cell transplantation

\section{Background}

Aplastic anemia (AA) is a bone marrow failure syndrome often present with pancytopenia. Patients with AA are at high risk of infection and hemorrhage. ${ }^{1}$ The incidence of AA in China is $\sim 7.4 / 10^{6}$, which is almost three times higher 
compared to Europe and North America. ${ }^{2,3}$ Severe AA (SAA) accounts for $\sim 18 \%,{ }^{4}$ with a characteristic of rapid disease progression and high mortality if left untreated. According to the guidelines and clinical practice, ${ }^{5}$ allogeneic hematopoietic stem cell transplantation (alloHSCT) and immune suppression therapy (IST) are the first treatment options for SAA, while disease-free survival (DFS) of HSCT is around $50-80 \%{ }^{6,7}$

Since 1964, traditional Chinese medicine (TCM) had been applied in the management of AA in China. The beneficial effect of TCM has also been confirmed in the treatment of aplastic anemia. ${ }^{8}$ And the combination of TCM with androgen or IST (cyclosporine with or without anti-thymoglobulin antibody) may significantly improve the overall response rate in patients with AA. ${ }^{9-12}$ In addition, our previous study revealed that the combination of TCM during the HSCT might reduce graft failure, transplant-related mortality and improve the 5 years overall survival. ${ }^{13}$ Yet, there are still limited data available on how and when the TCM should be applied. In addition, the principle of TCM during different stages of stem cell transplantation remains unclear.

The basic TCM syndrome is based on "qi and blood", "Yin and Yang", "deficiency and excess", and "exterior and interior", also known as "eight principles". "Yin and Yang" differentiation is the general and main principle. To better understanding the material basis of TCM syndrome, many studies have disclosed the correlation of syndrome differentiation with objective indicators, including endocrine hormone (adrenocorticosteroids, thyroid hormones, prostaglandins), plasma cyclic nucleotides (cAMP, cGMP, and their dynamic balance), as well as energy metabolism situation, ${ }^{14,15}$ which have been applied as the evaluation index for TCM treatment. ${ }^{16,17}$ However, TCM syndrome is complex, and the syndrome evolution is not always clear. During the HSCT, we found that the changing of TCM syndrome occurred much more rapidly, and the deviation of "Yin" and "Yang" were more obvious, thus suggesting that HSCT can also be an ideal disease model for observing TCM syndrome evolution and verifying the material basis of "Yin", "Yang", as well as "blood stasis" syndrome in our AA patients. Herein, we investigated the evolution and characteristics of TCM syndromes in SAA patients undergoing HSCT, and also analyzed the correlation with the objective indicators, which may profit from developing a TCM treatment proposal for HSCT.

\section{Materials and Methods}

\section{Participants and Recruitment}

A total of 18 patients with SAA who underwent HSCT between December 2015 and January 2017 were recruited in the First Affiliated Hospital of Zhejiang Chinese Medical University, Hangzhou, Zhejiang, China. Twelve of them were male (12/18), with a median age of 28.5 (1153) years, and 12 of them progressed from non-SAA. All the patients met the diagnostic and severity assessment criteria for SAA. ${ }^{18}$ The syndrome differentiation was made according to the "Revised Edition of Guidelines for The Clinical Diagnosis and Treatment of Aplastic Anemia (Sui Lao)" issued by the National Administration of Traditional Chinese Medicine in 2013. ${ }^{19}$ Moreover, 21 healthy subjects without obvious syndrome deviation (equilibrium in Yin and Yang) were included as normal control for peripheral serum and urine detection, 11 males (11/21), with a median age of 39 (2153) years. In addition, five bone marrow samples from normal bone marrow transplantation donors were also prepared as control bone marrow samples.

\section{Sources of Stem Cell}

Donors were selected based on the best available human leukocyte antigen (HLA) match at the time of transplantation. HLA-A, B, C DRB1, and DQB1 loci were confirmed by the high-resolution molecular method. Six (6/18) patients were grafted from matched sibling donors, 7 (7/ 18) from matched unrelated donors from the China Marrow Donor Program (CMDP), 4 (4/18) from haploidentical donors, and $1(1 / 18)$ from a mismatched related donor.

\section{Conditioning Regimen}

All 18 patients received the same conditioning regimen: fludarabine (Flu) $30 \mathrm{mg} / \mathrm{m}^{2} \times 5$ days, rabbit antithymoglobulin antibody (ATG) $2.5 \mathrm{mg} / \mathrm{kg} \times 4$ days, cyclophosphamide (CY) $100-120 \mathrm{mg} / \mathrm{kg}$ in total (given in 2 or 3 days).

\section{GVHD Prophylaxis}

GVHD prophylaxis consisted of mycophenolate mofetil (MMF) $1200-1500 \mathrm{mg} / \mathrm{m}^{2}$, cyclosporine (target trough concentration $200-300 \mathrm{ng} / \mathrm{mL}$ ) per day, and methotrexate (MTX $15 \mathrm{mg} / \mathrm{m}^{2}$ on day +1 , and $10 \mathrm{mg} / \mathrm{m}^{2}$ on day $+3,+6$, and +11$)$. 


\section{Aplastic Anemia (AA) TCM Syndrome Diagnosing and Scoring}

Diagnosing TCM syndrome in AA was done according to "Revised Edition of Guidelines for The Clinical Diagnosis, and Treatment of Aplastic Anemia (Sui Lao)", ${ }^{19}$ which included heat-toxin congestion and excessiveness syndrome, Yin deficiency and blood heat syndrome (spleen) kidney yang deficiency syndrome, (liver) kidney Yin deficiency syndrome, and kidney Yin and Yang deficiency syndrome. symptoms of the major syndrome included a pale face, dizziness, palpitations, and shortness of breath; symptoms of the minor syndrome included feverish palms and soles, hectic fever and night sweating, dipsia, yellow urine, cold body, anorexia, and diarrhea. All symptoms were scored according to the severity (light, moderate or severe): 0, 2, 4, and 6 points, or $0,1,2$, and 3 points ${ }^{10}$ (Table 1). The assessment and scoring of TCM syndrome were performed 10 days before stem cell reinfusion $(-10 \mathrm{~d})$, the day before stem cell reinfusion $(-1 \mathrm{~d}), 7$ days after stem cell reinfusion $(+7 \mathrm{~d})$, and on $+14 \mathrm{~d},+30 \mathrm{~d},+60 \mathrm{~d}$, and $+90 \mathrm{~d}$.

\section{Blood Stasis Syndrome Evaluation and Scoring}

The diagnosis of blood stasis syndrome included the inspection of the tongue, facial and skin, pain assessment, degree of hemorrhage evaluation, assessing consciousness, mental and bodily sensation, pulse manifestation, and abdominal mass evaluation. According to the severity (light, moderate or severe), syndromes were scored with $0,1,2$, and 3 points (Table 2). With an overall score over 4 , the diagnosis of blood stasis syndrome was confirmed. The assessment and scoring of stasis syndrome were performed on $-10 \mathrm{~d},-1 \mathrm{~d},+7 \mathrm{~d},+14 \mathrm{~d},+30 \mathrm{~d},+60 \mathrm{~d}$, and $+90 \mathrm{~d}$.

\section{Collection and Preparing of Clinical Specimens}

The peripheral blood $(10 \mathrm{~mL})$, urine $(5 \mathrm{~mL})$, and bone marrow $(10 \mathrm{~mL})$ were collected from each patient and volunteer. After centrifugation, serum, urine, and marrow mononuclear cells were prepared and frozen in $-70^{\circ} \mathrm{C}$ for further use.

\section{ELISA Assay}

Approximately $0.5 \mathrm{~mL}$ serum was taken from each group for single detection. Serum cyclic adenosine monophosphate (cAMP), cyclic guanosine monophosphate (cGMP), thyroxine (total triiodothyronine, free triiodothyronine, total tetraiodothyronine, and free tetraiodothyronine), iron load indicator (ferritin and labile plasma iron), and its regulator iron metabolism indicators (hepcidin, soluble transferrin receptor, and ferroportin) were detected after each time

Table I Scoring System for Basic TCM Syndrome

\begin{tabular}{|c|c|c|c|c|c|}
\hline \multicolumn{2}{|l|}{ Symptom } & \multicolumn{4}{|c|}{ Scoring } \\
\hline & & $\begin{array}{l}\text { None } \\
(0)\end{array}$ & $\begin{array}{l}\text { Mild (2 for Major } \\
\text { Syndromes, and I for } \\
\text { Minor) }\end{array}$ & $\begin{array}{c}\text { Moderate (4 for Major } \\
\text { Syndromes, and } 2 \text { for Minor) }\end{array}$ & $\begin{array}{c}\text { Severe (6 for Major } \\
\text { Syndromes, and } 3 \text { for Minor) }\end{array}$ \\
\hline $\begin{array}{l}\text { Major } \\
\text { syndromes }\end{array}$ & $\begin{array}{l}\text { Pale face } \\
\text { Dizziness } \\
\text { Fatigue } \\
\text { Palpitations and } \\
\text { shortness of breath }\end{array}$ & & $\begin{array}{l}\text { Slightly } \\
\text { Occasionally } \\
\text { Slightly, can still work on daily } \\
\text { life } \\
\text { Occasionally }\end{array}$ & $\begin{array}{l}\text { Moderate, pale without vitality } \\
\text { Frequently } \\
\text { Moderate, hard to work } \\
\text { Frequently }\end{array}$ & $\begin{array}{l}\text { Severe, pale with a white paper } \\
\text { looking } \\
\text { Persistently and hard to relieve } \\
\text { Severe, can only stay in bed } \\
\text { Recurrently and hard to relieve }\end{array}$ \\
\hline $\begin{array}{l}\text { Minor } \\
\text { syndromes }\end{array}$ & $\begin{array}{l}\text { Feverish palms and } \\
\text { soles } \\
\text { Hectic fever and night } \\
\text { sweating } \\
\text { Dipsia } \\
\text { Yellow urine } \\
\text { Cold body } \\
\text { Anorexia } \\
\text { Diarrhea }\end{array}$ & & $\begin{array}{l}\text { Slightly feverish in night } \\
\text { Occasionally, mostly on head } \\
\text { Occasionally } \\
\text { Primrose yellow } \\
\text { Cold in hands and feet } \\
\text { Slightly, appetite decreases } 1 / 3 \\
\text { to } 2 / 3 \\
\text { Once daily }\end{array}$ & $\begin{array}{l}\text { Moderate feverish with vexation } \\
\text { Recurrently, on chest and waist } \\
\text { Frequently, tolerable } \\
\text { Medium yellow } \\
\text { Cold limbs } \\
\text { Bad, appetite decreases above } 2 / 3 \\
\text { Two to three times daily }\end{array}$ & $\begin{array}{l}\text { Feel burning, and away from } \\
\text { clothing } \\
\text { Frequently, showing as wet body } \\
\text { Frequently, intolerable } \\
\text { Dark yellow } \\
\text { Clod body, cannot relieve with } \\
\text { warming } \\
\text { Severe anorexia, even no diet } \\
\text { More than three times daily }\end{array}$ \\
\hline
\end{tabular}


Table 2 Scoring System for Stasis Syndrome

\begin{tabular}{|c|c|c|c|c|}
\hline & \multicolumn{4}{|c|}{ Grading and Scoring } \\
\hline & Normal (0) & Mild (I) & Medium (2) & Severe (3) \\
\hline $\begin{array}{l}\text { Inspection of } \\
\text { the tongue }\end{array}$ & $\begin{array}{l}\text { Pink tongue, without } \\
\text { ecchymosis and } \\
\text { sublingual varices }\end{array}$ & $\begin{array}{l}\text { Dark red tongue, with } \\
\text { petechiae }\end{array}$ & $\begin{array}{l}\text { Dark purple tongue, with } \\
\text { petechiae and ecchymosis }\end{array}$ & $\begin{array}{l}\text { Bluish purple tongue, or with } \\
\text { sublingual varices }\end{array}$ \\
\hline $\begin{array}{l}\text { Inspection of } \\
\text { the facial }\end{array}$ & $\begin{array}{l}\text { No purplish black at } \\
\text { face, lips, gums or eyes }\end{array}$ & Dark red less than two sites & $\begin{array}{l}\text { Dark red or bluish purple } \\
\text { more than two sites }\end{array}$ & Purple black more than two sites \\
\hline $\begin{array}{l}\text { Skin } \\
\text { manifestation }\end{array}$ & $\begin{array}{l}\text { No rough skin nor } \\
\text { scales }\end{array}$ & $\begin{array}{l}\text { Rough hand and foot, but } \\
\text { without scales }\end{array}$ & $\begin{array}{l}\text { Rough hand and foot, with } \\
\text { scales }\end{array}$ & $\begin{array}{l}\text { Rough skin throughout the body with } \\
\text { scales }\end{array}$ \\
\hline Pain & $\begin{array}{l}\text { No fixed pain, prickling } \\
\text { or cramping }\end{array}$ & $\begin{array}{l}\text { Occasionally pain, and always } \\
\text { relieved within half an hour }\end{array}$ & $\begin{array}{l}\text { Pain sometimes, always } \\
\text { relieved within three hours, } \\
\text { and no need for drug }\end{array}$ & Persistent pain, and painkillers needed \\
\hline Bleeding & $\begin{array}{l}\text { No bleeding, } \\
\text { hypodermic } \\
\text { ecchymosis, nor } \\
\text { menstrual disorders }\end{array}$ & $\begin{array}{l}\text { Small petechiae in one site, or } \\
\text { with occasionally } \\
\text { dysmenorrhea and dark } \\
\text { menstruation }\end{array}$ & $\begin{array}{l}\text { Petechiaes more than two } \\
\text { sites, or always with } \\
\text { dysmenorrhea and dark } \\
\text { menstruation }\end{array}$ & $\begin{array}{l}\text { Petechiaes more than three sites, or } \\
\text { suffer from abdominal pain during } \\
\text { menstruation, and even amenorrhea }\end{array}$ \\
\hline Conscious & No vertigo or forgetful & Occasionally happen & $\begin{array}{l}\text { Happened sometimes, and } \\
\text { more frequently after physical } \\
\text { work }\end{array}$ & Always happen, and even during rest \\
\hline Mentality & No mental abnormality & $\begin{array}{l}\text { Occasionally happen, and } \\
\text { relieved without intervene }\end{array}$ & $\begin{array}{l}\text { Happened sometimes, and } \\
\text { can be stopped by persuading }\end{array}$ & $\begin{array}{l}\text { Always happen, and can only stopped } \\
\text { by constraint or medication }\end{array}$ \\
\hline $\begin{array}{l}\text { Physical } \\
\text { sensation }\end{array}$ & $\begin{array}{l}\text { No numbness or } \\
\text { hemiplegia }\end{array}$ & $\begin{array}{l}\text { Occasionally happen, and } \\
\text { relieved without intervene }\end{array}$ & $\begin{array}{l}\text { Numbness cannot be alleviate } \\
\text { by self, with mild hemiplegia }\end{array}$ & Numbness Limbs and with hemiplegia \\
\hline $\begin{array}{l}\text { Pulse } \\
\text { manifestation }\end{array}$ & Normal pulse & Hesitant pulse & Thread and hesitant pulse & No pulse or irregularly pulse \\
\hline $\begin{array}{l}\text { Lump in } \\
\text { abdomen }\end{array}$ & $\begin{array}{l}\text { No organ enlargement, } \\
\text { mass, tissue } \\
\text { hyperplasia, new } \\
\text { organisms, etc. }\end{array}$ & $\begin{array}{l}\text { Slightly stiff and painful with } \\
\text { pressing }\end{array}$ & Moderate stiff and painful & Painful and reject pressing \\
\hline
\end{tabular}

point (totally seven times). The levels of bone marrow vascular endothelial growth factor (VEGF), nitric oxide synthase (NOS), and reactive oxygen species (ROS) were detected before HSCT and monthly after HSCT (totally four times). All detection was performed according to the manufacturer's protocol of the ELISA kit.

\section{Statistical Analysis}

The compiled data were first inputted into the Excel spreadsheet and were then read into SPSS15.0 biometric statistical software program for further analysis. Normal data were expressed as mean \pm standard deviation, and nonnormal data were expressed as medians (interquartile range). Variance and pairwise comparisons were used for normal data, whereas non-normal data were subjected to non-parametric tests. The Kruskal-Wallis $H$-test was used for pairwise comparisons and the Mann-Whitney $U$-test for multiple comparisons. Binary variable regression models were used to analyze the correlation among objective factors and TCM syndromes. A P value $<0.05$ was considered to be statistically significant.

\section{Results}

\section{Syndrome Differentiation Based on "Yin- Yang" and "Zang-Fu Viscera"}

Patients were primarily diagnosed with "Yin" or "Yang" deficiency syndrome, and further syndrome differentiation was performed based on "Zang-Fu viscera". Yin deficiency 
syndrome was differentiated into "kidney Yin deficiency", "liver-kidney Yin deficiency" and "kidney Yin and Yang deficiency" syndromes, and Yang deficiency syndrome was differentiated into "kidney Yang deficiency", "spleen-kidney Yang deficiency", "kidney Yin and Yang deficiency" syndromes, respectively. After careful assessment of the TCM syndrome and scoring, we found that before HSCT (-10d), the syndrome was more likely "Yin deficiency" or "Yang deficiency", rather than "Yin and Yang deficiency". During the conditional stage ( $-10 \mathrm{~d}$ to $-1 \mathrm{~d})$, more patients manifested "kidney Yin and Yang deficiency" syndrome. Moreover, after stem cell engraftment $(+14 \mathrm{~d})$, more "spleen-kidney Yang deficiency" syndrome was seen. Finally, 2 months after stem cell reinfusion, the TCM syndrome became stable and mainly manifested as "kidney Yang deficiency" or "spleen-kidney Yang deficiency" syndrome (Table 3, Figure 1).

\section{Blood Stasis Syndrome Evaluation During HSCT}

The scoring of blood stasis syndrome was performed at the corresponding time point during HSCT. A total of $61 \%$ (11/ 18) patients were complicated with stasis syndrome before HSCT (score $>4$ ). During the transplantation conditioning, the stasis score further increased and peaked 7 days after stem cell reinfusion $(+7 \mathrm{~d})$; however, no significant differences were observed $(\mathrm{P}>0.05)$. After the stem cell engraftment (around $+14 \mathrm{~d}$ ), the stasis score decreased $(\mathrm{P}<0.01)$ and was kept at the same level (score $\leq 4$ ) during $+60 \mathrm{~d} \sim+90 \mathrm{~d}$. At $+90 \mathrm{~d}$, the stasis score decreased to the minimum value, and $88.9 \%(16 / 18)$ had no symptoms of stasis (Table 4, Figure 2).

\section{Typical Evolution of Tongue Manifestation During HSCT}

Tongue manifestations have a crucial role in TCM syndrome differentiation. During the syndrome assessment, we also recorded and compared the tongue manifestation. Three typical evolution (Type I:2A-2E; Type II:2F-2J; Type III:2K-2O) of tongue manifestation during the process of HSCT are shown in Figure 3. The evolution of TCM syndrome of Type I went from the firstly "spleen-kidney Yang deficiency" stage to "liver-kidney Yin deficiency with blood stasis" stage, "spleen-kidney Yang deficiency with blood stasis" stage, and finally of relatively stable "kidney Yang deficiency" stage. In Type II, the syndrome evolution was as follows: "kidney Yang deficiency", to a syndrome of "Yin deficiency with blood stasis", to "spleen-kidney Yang

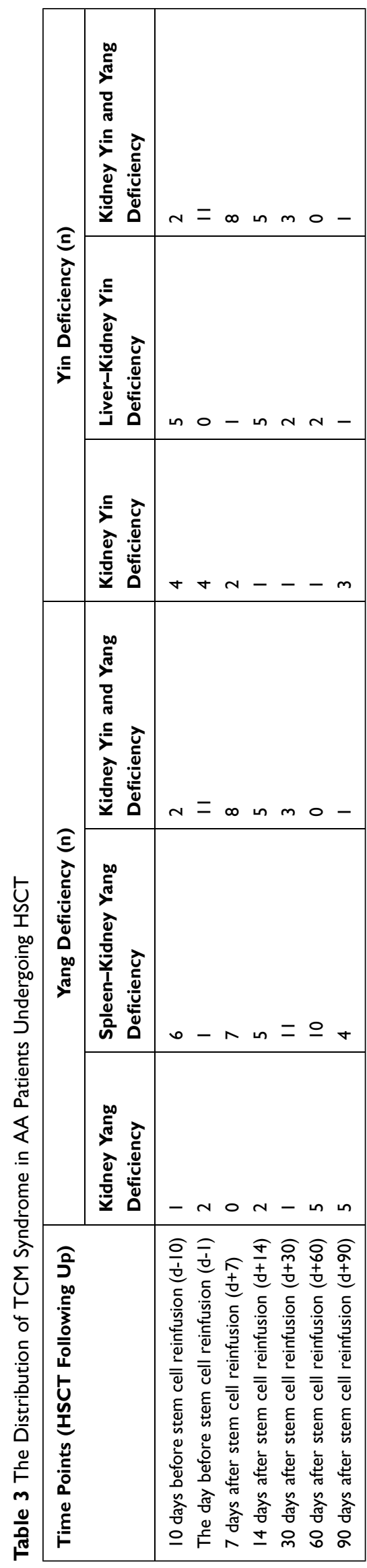




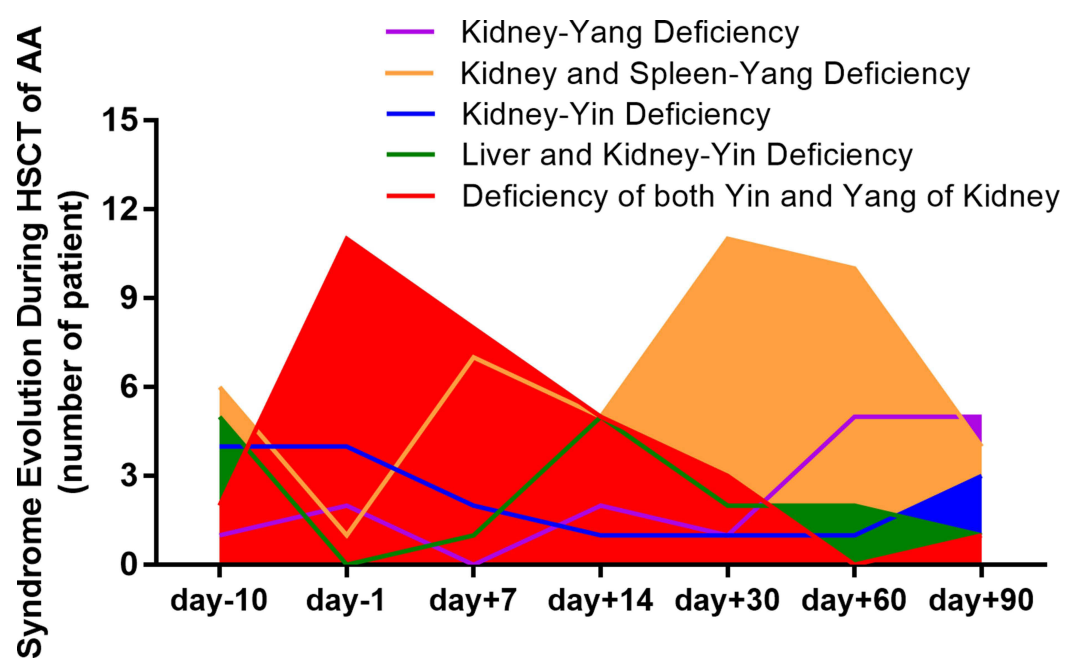

Figure I Evolution of TCM syndromes in severe aplastic anemia (SAA) patients undergoing allogeneic hematopoietic stem cell transplantation (HSCT) based on "Yin-Yang" and "Zang-Fu viscera" syndrome differentiation.

deficiency" and finally "kidney Yang deficiency" stage. In Type III, the syndrome evolution was as follows: "kidney Yin deficiency", to "Yin deficiency fire hyperactivity", to "Yin and Yang deficiency", and finally "kidney Yang deficiency" stage.

\section{Changes of Serum cAMP and cGMP During the HSCT Process}

The expression level of serum cAMP in the patient was relatively equal to the normal control, while the cGMP was significantly higher $(\mathrm{P}<0.01)$. During the process of HSCT, the cAMP remarkably decreased from day -1 , and then reached the lowest level at day $-60(\mathrm{P}<0.01)$. It then relatively increased at day -90 . No differences were observed among day $+30,+60$, and $+90(\mathrm{P}>0.05)$. For the cGMP, similar changes were observed. The cGMP decreased after the conditioning regimen and tended to stabilize after day +14 , but the level was still higher than the normal control $(\mathrm{P}<0.01)$ (Figure 4).

Table 4 Comparison of Stasis Score Among Different Time Point After During HSCT (Wilcoxon), P value

\begin{tabular}{|l|l|l|l|l|}
\hline & Day I4 & Day+30 & Day+60 & Day+90 \\
\hline Day-10 & NS & 0.011 & 0.001 & 0.002 \\
Day-I & NS & 0.005 & 0.001 & 0.001 \\
Day+7 & 0.013 & 0.003 & 0.001 & 0.000 \\
Day I4 & $I$ & 0.05 & 0.015 & 0.007 \\
Day+30 & 0.05 & $I$ & NS & 0.047 \\
Day+60 & 0.015 & NS & $I$ & NS \\
Day+90 & 0.007 & 0.047 & NS & $/$ \\
\hline
\end{tabular}

\section{Changes of Urine 17-OH-CS During HSCT Process}

The urine level of 17-OH-CS in AA before HSCT was significantly higher than the normal group $(\mathrm{P}<0.01)$. After transplantation conditioning, the 17-OH-CS gradually decreased over time; the lowest level was observed after day +60 , after which it remained stable until +90 (Figure 4).

\section{Changes of Serum Thyroxine During HSCT Process}

The serum level of total triiodothyronine (TT3), tetraiodothyronine (TT4), and free T3 (FT3), T4 (FT4) were detected during the HSCT. The TT3 and FT3 were significantly lower in AA before HSCT; the level decreased over time (from day-1 to day+30) after transplantation. Sixty to 90 days after stem cell reinfusion, the TT3 and FT3 remarkably increased $(\mathrm{P}<0.05)$ and reached the same level detected before HSCT (Figure 5A). For the TT4 and FT4, the expression level did not have a great change during the HSCT, but they decreased on day +30 and day $+60(\mathrm{P}<0.05$ or $\mathrm{P}<0.01)$ when compared to the level at the early stage of HSCT (day -10 to day +7 ) (Figure 5B).

\section{Comparison of Iron Load and Its Regulator During HSCT Process}

The serum level of iron load indexes, ferritin and labile plasma iron (LPI), as well as iron-absorbing regulators, hepcidin and soluble transferrin receptor (sTfR), were significantly higher in AA patients than the normal 


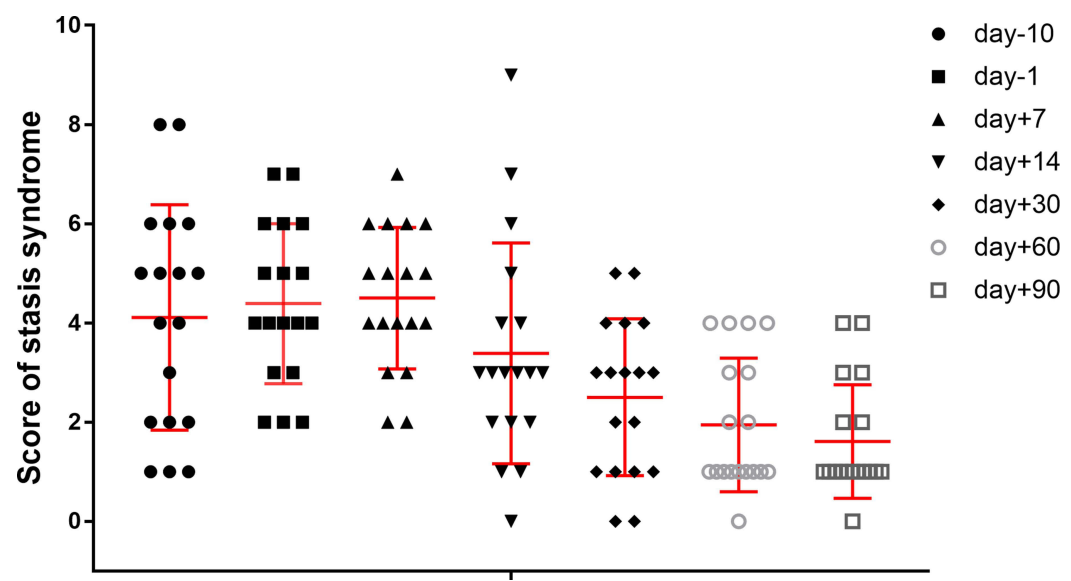

Figure 2 Evolution of "blood stasis" syndrome in SAA patients during HSCT. The stasis syndrome was differentiated, scoring and compared during different stage of HSCT. A total of $61 \%(1 / / 18)$ patients were complicated with stasis syndrome before HSCT, and increased after conditioning. After the stem cell engraftment (around +14d), the stasis score decreasing and $88.9 \%(16 / 18)$ had no symptoms of stasis at $+90 \mathrm{~d}$.

-10day

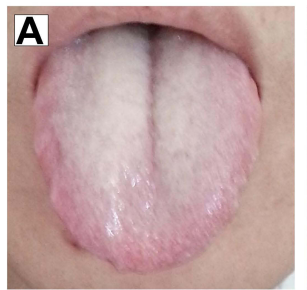

Type I

Type II

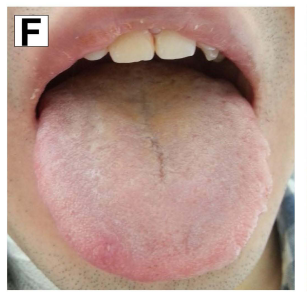

K

Type III

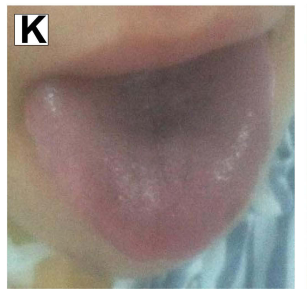

-1 day
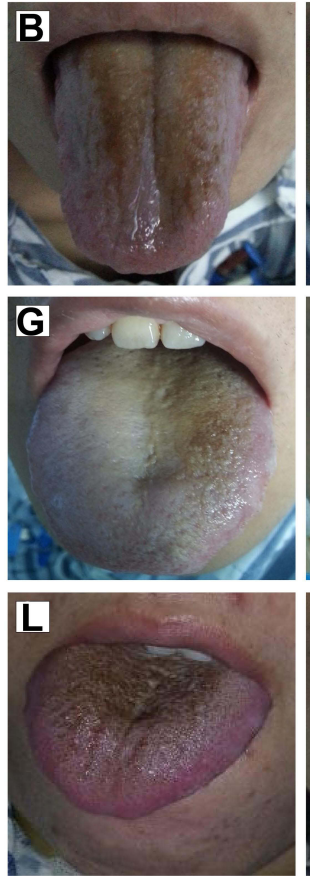

+14 day
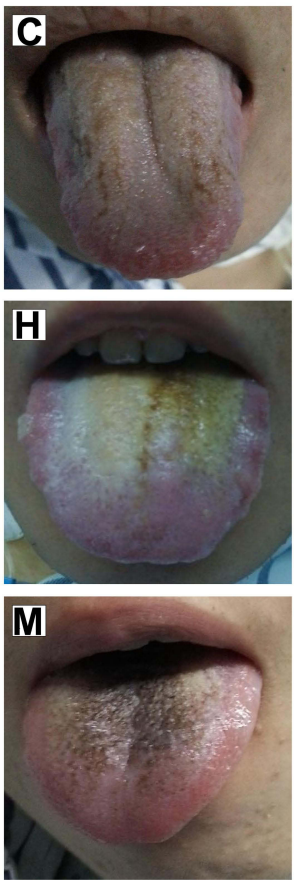

+60day
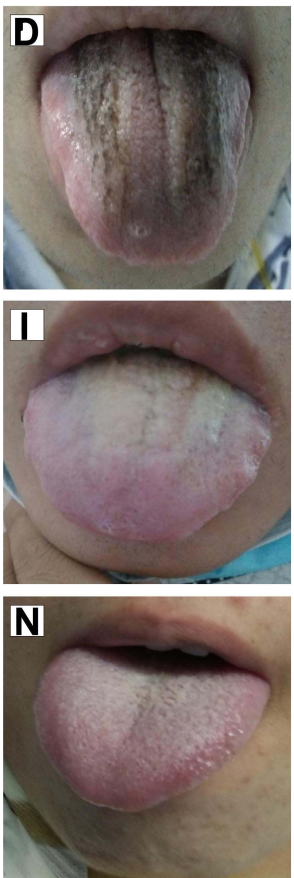

+90day
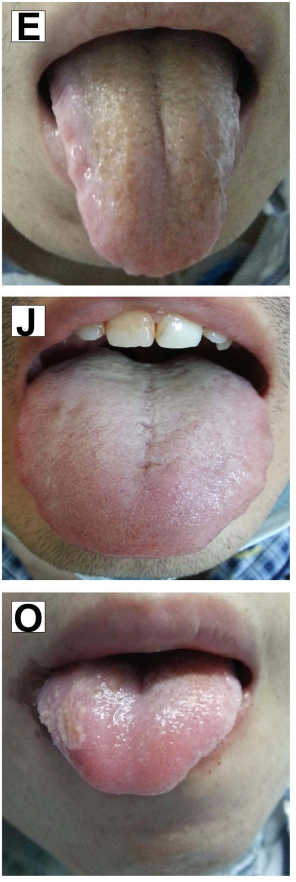

Figure 3 Typical evolution of tongue manifestation during HSCT. Type I: went from the firstly "spleen-kidney Yang deficiency" stage to "liver-kidney Yin deficiency with blood stasis" stage, "spleen-kidney Yang deficiency with blood stasis" stage, and finally of relatively stable "kidney Yang deficiency" stage (2A-2E); Type II: went from "kidney Yang deficiency", to a syndrome of "Yin deficiency with blood stasis", to "spleen-kidney Yang deficiency" and finally "kidney Yang deficiency" stage (2F-2f); and Type III: went from "kidney Yin deficiency", to "Yin deficiency fire hyperactivity", to "Yin and Yang deficiency", and finally "kidney Yang deficiency" stage (2K-2O).

population before HSCT, while ferroportin (FPN) was much lower $(\mathrm{P}<0.05$ or $\mathrm{P}<0.01)$. Moreover, after transplantation, the ferritin and LPI gradually decreased over time and then became stable after $+60 \mathrm{~d}$. The LPI reached the lowest point on day +60 (Figure 6A). The change in hepcidin was much slower than ferritin, which obviously decreased 30 days after stem cell reinfusion $(\mathrm{P}<0.05$ or
$\mathrm{P}<0.01$ ), while FPN gradually increased after day +7 $(\mathrm{P}<0.05$ or $\mathrm{P}<0.01)$ (Figure 6B).

\section{Changes of Bone Marrow VEGF, NOS, and ROS During HSCT Process}

The impairment of iron deposition is mainly mediated by oxygen-free radical damage. In this study, the marrow 


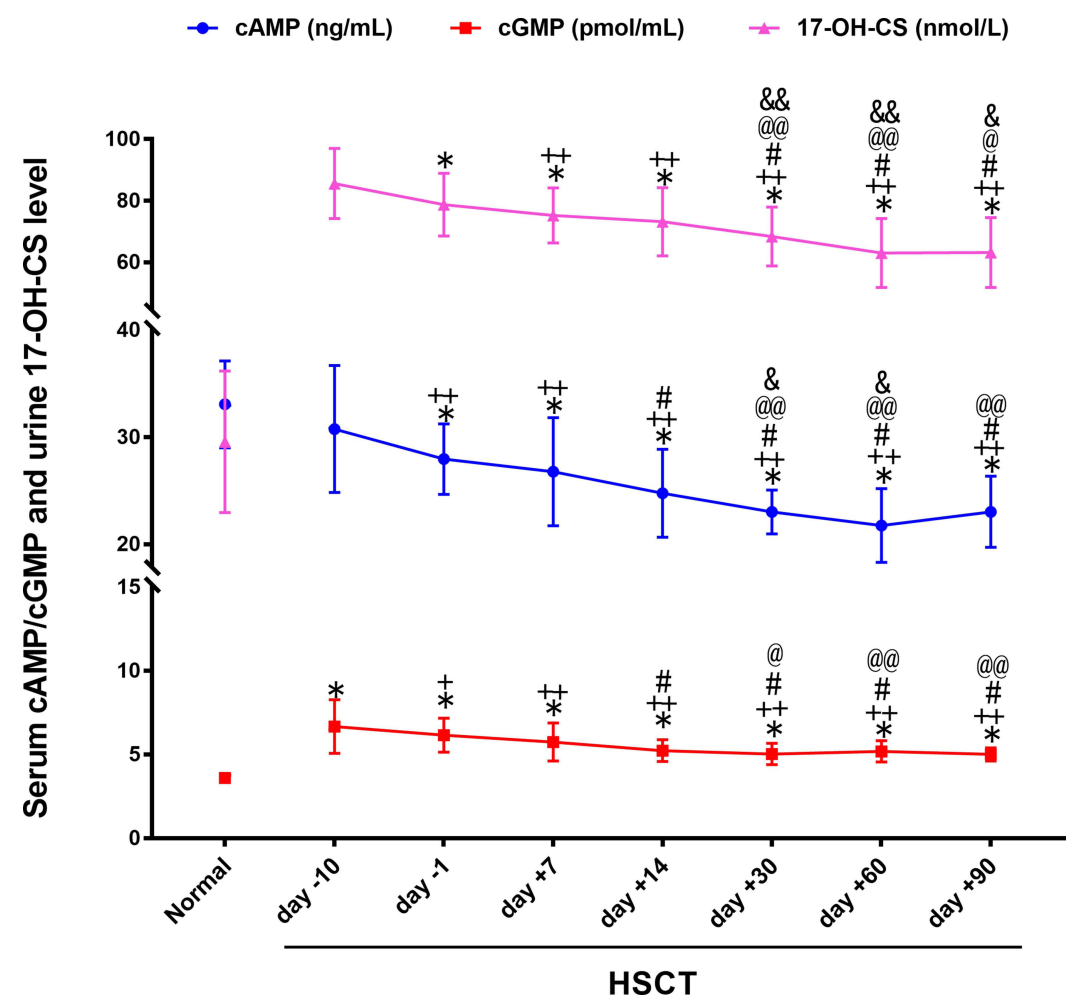

Figure 4 Changes of serum cAMP, cGMP and urine $17-\mathrm{OH}-\mathrm{CS}$ during the HSCT process. Data are presented as mean \pm SD; $* P<0.0 \mathrm{I}$ (as compared with the normal population); ${ }^{+} P<0.05$, and ${ }^{++} P<0.01$ (as compared with-10d); ${ }^{\#} P<0.01$ (as compared with $-I d$ ); ${ }^{@} P<0.05$, $@^{@} P<0.01$ (as compared with $+7 \mathrm{~d}$ ); ${ }^{\&} P<0.05$, and ${ }^{\& \&} P<0.01$ (as compared with $+14 d$ ).

serum level of VEGF, NOS, and ROS was detected. The expression of VEGF in bone marrow from AA patients was significantly lower, while NOS and ROS were much higher than the normal subjects (all $\mathrm{P}<0.01$ ). After HSCT, the VEGF remarkably increased after +60 days, and NOS and ROS decreased after +30 days $(\mathrm{P}<0.01)$ (Figure 7 ).

\section{Correlation Analysis Between TCM Syndrome Evolution and Serum Indicators}

To analyze the indicator of "Yin" and "Yang" syndrome, we deleted the patient without obvious "Yin" and "Yang" deviation during the HSCT. Patients with "Deficiency of both Yin and Yang" were assigned into "Yin" deficiency and "Yang" deficiency group. The Spearman coefficient analysis was used to assess the cross-correlation of "Yin", "Yang" deficiency syndrome, "blood stasis" syndrome with metabolism indicators (cAMP, cGMP, 17-OH-CS, and thyroxine) as well as iron-related indicators (ferritin, LPI, Hepcidin, sTfR, and FPN). Results showed that "Yang deficiency" was significantly negatively correlated with TT3, FT3, and TSH, while "Yin deficiency" syndrome had a strong positive correlation with cGMP, 17-OH-CS, LPI, hepcidin, and sTfR (Tables 5 and 6). Considering "blood stasis" syndrome, it showed a remarkable positive correlation to cAMP, cGMP, 17$\mathrm{OH}-\mathrm{CS}$, hepcidin, sTfR, and a negative correlation to FPN (Tables 7 and 8).

\section{Discussion}

Our data suggested that the main syndrome of a newly diagnosed patient with SAA was "Yin deficiency with fire hyperactivity" or "heat toxic exacerbation", ${ }^{20}$ while those with non-severe chronic AA presented with "kidney deficiency with blood stasis". ${ }^{10}$ For patients who were planning to receive stem cell transplantation, the severe infection was kept under control, and the "Heat Toxic" syndrome was alleviated before HSCT. In this study, we found that the $9 / 18$ patients were diagnosed with "Yang deficiency" and 11/18 with "Yin deficiency" before conditioning (two of them deficient in both Yin and Yang). For patients with "Yang deficiency", 66.7\% were diagnosed with "spleen-kidney Yang deficiency", while in "Yin deficiency" group, "kidney Yin deficiency" (36\%) and "liver-kidney Yin deficiency" (45\%) occupied the 
A

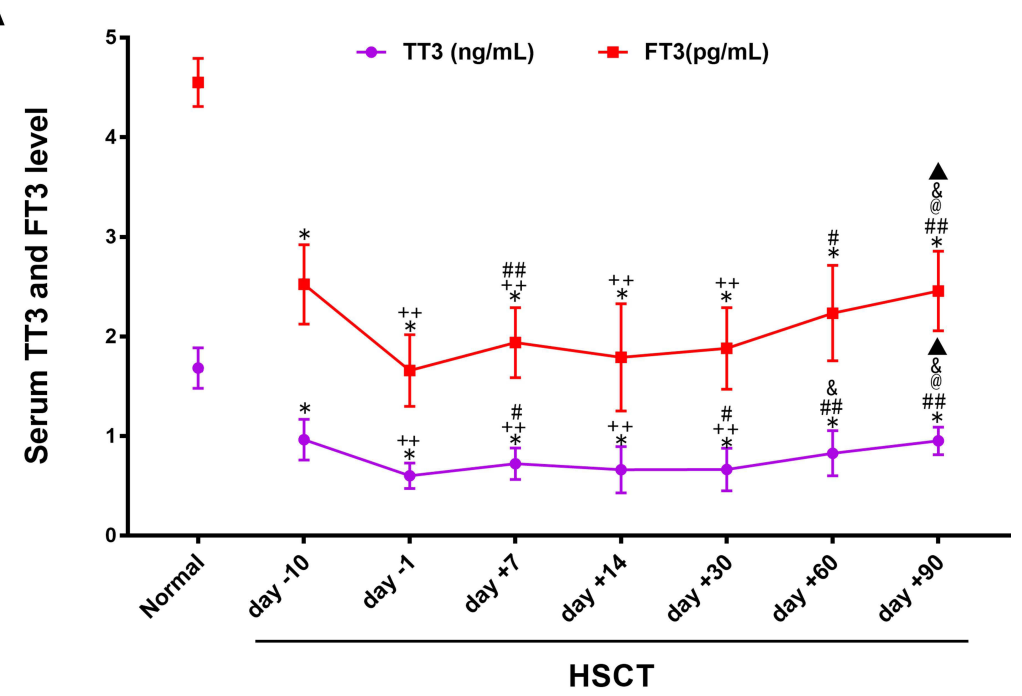

B

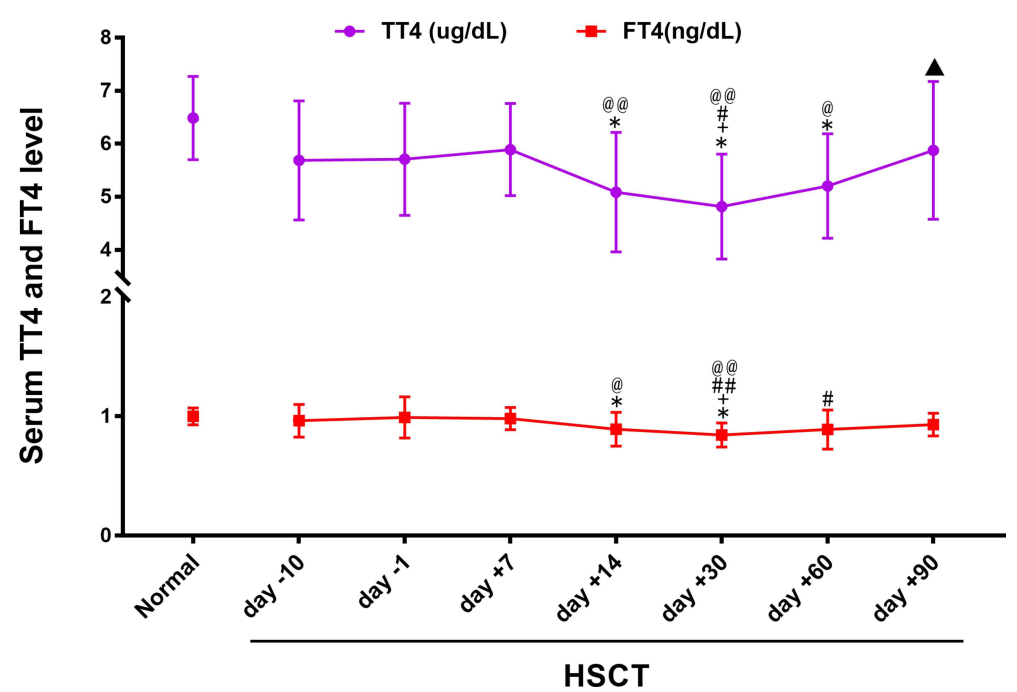

Figure 5 Changes of serum thyroxine during HSCT process. The serum level of total triiodothyronine (TT3), free T3 (FT3) (A) and tetraiodothyronine (TT4), free T4 (FT4) (B) were detected during the HSCT. Data are presented as mean $\pm \mathrm{SD} ; * P<0.01$ (as compared with the normal population); ${ }^{+} P<0.05$, and ${ }^{++} P<0.01$ (as compared with -10d); ${ }^{\#} P<0.05,{ }^{\#} P<0.01$ (as compared with $-\mathrm{Id}$ ); ${ }^{@} P<0.05$, @@ $P<0.0$ I (as compared with +7d); ${ }^{\circledR} P<0.0 \mathrm{I}$ (as compared with +l4d); $\Delta P<0.0 \mathrm{I}$ (as compared with $+30 d)$.

majority. After conditioning, the proportion of "Kidney Yin and Yang deficiency" increased to $61.6 \%$ and decreased after stem cell transfusion. Fourteen days after stem cell transfusion, the TCM syndrome gradually developed into "spleen-kidney Yang deficiency". The proportion reached the peak at +30day $(61.1 \%)$ and became stable after +60 day. On +90 day, the majority of patients were diagnosed with "kidney Yang deficiency" (35.7\%) or "spleen-kidney Yang deficiency" (28.6\%), and four patients manifested with no obvious "Yin" or "Yang" deviation. Our research presented a whole syndrome map during HSCT for a patient without severe complications.
The cyclic nucleotides (cAMP and cGMP) act as intercellular second messengers by stimulating hormones, neurotransmitters, and inflammatory mediators. ${ }^{21}$ cAMP is considered as "Yang", and cGMP as "Yin" in "Yang deficiency" model, which can be restored by warming and recuperating kidney yang. ${ }^{22-24}$ However, cAMP and cGMP function may differ in different syndrome or disease models. It is reported that in patients with "Yang deficiency" physique, the serum cGMP increased and cAMP/cGMP decreased after Yang nourishment, while no changes in cAMP were observed. ${ }^{25}$ Besides cyclic nucleotides, the hypothalamic-pituitary-adrenal (HPA) axis dysfunction has a crucial role in the pathological 
A

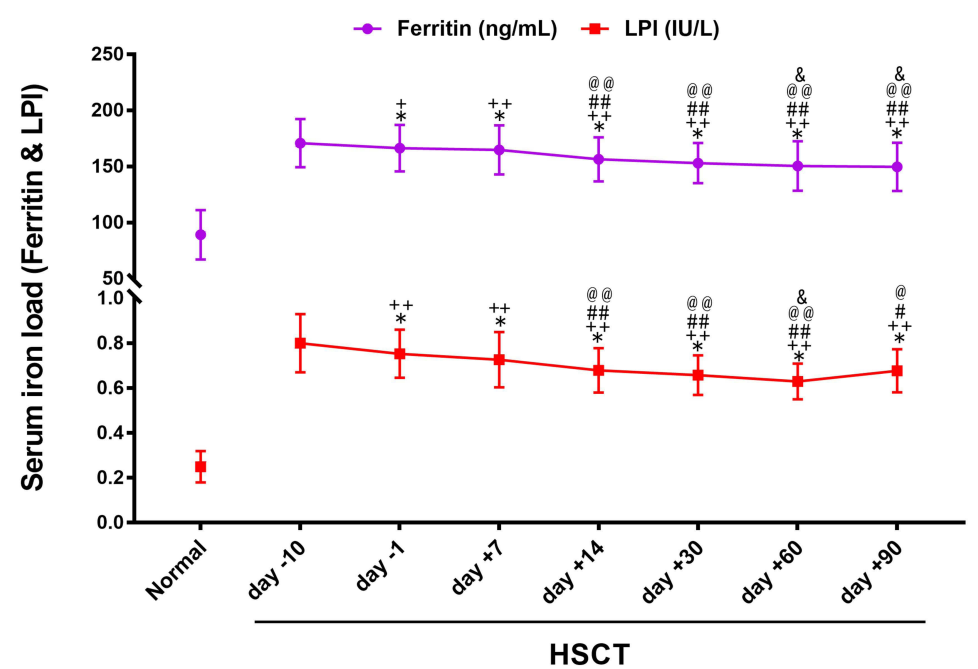

B

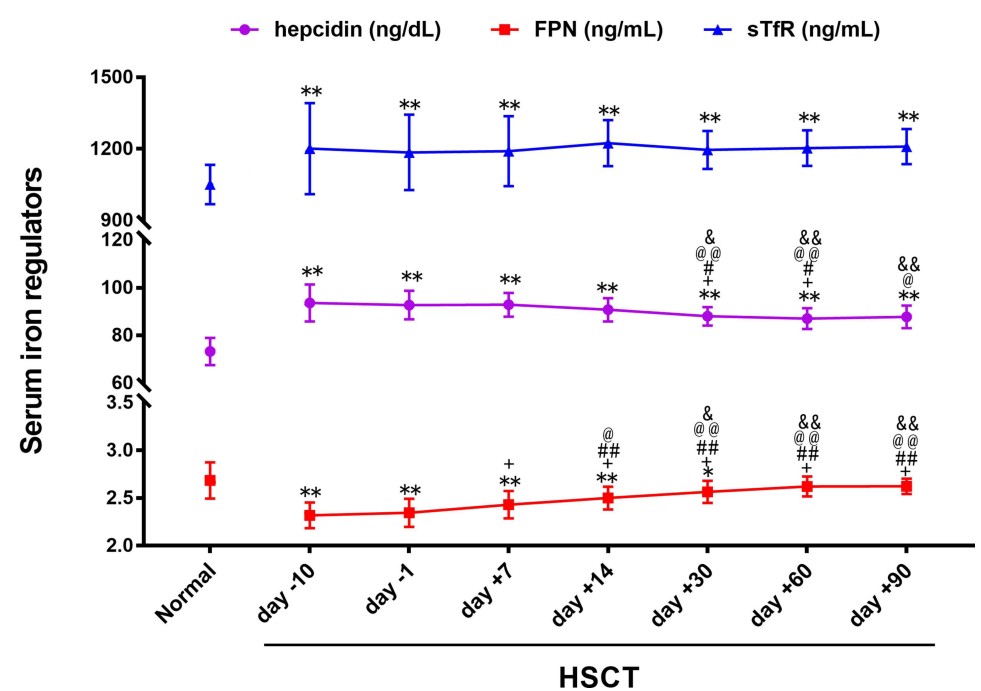

Figure 6 Comparison of iron load and its regulator during HSCT process. The serum level of iron load indexes, ferritin and labile plasma iron (LPI) (A), as well as ironabsorbing regulators, hepcidin and soluble transferrin receptor (sTfR) (B) were detected. Data are presented as mean \pm SD; $* P<0.05$, $* * P<0.0$ I (as compared with the normal population); ${ }^{+} P<0.05$, and ${ }^{++} P<0.01$ (as compared with $-10 \mathrm{~d}$ ); ${ }^{\#} P<0.05,{ }^{\# \#} P<0.01$ (as compared with $-\mathrm{Id}$ ); ${ }^{@} P<0.05$, ${ }^{@ @ P} P<0.0 \mathrm{I}$ (as compared with +7d); ${ }^{\circledR} P<$ 0.05 , and ${ }^{\& \&} p<0.01$ (as compared with $+14 d$ ).

basis of "Kidney Yang Deficiency". ${ }^{23,26}$ Our results showed that the SAA patient had a significantly higher cGMP level and lower cAMP than the normal subjects; cGMP and cAMP remarkably decreased after conditioning. After stem cell reinfusion, the cGMP became stable since +14 day, and cAMP recovered around +90day. In addition, patients also had a higher level of 17-OH-CS, which decreased during the HSCT, and became stable around +60-+90day. The correlation analysis showed a positive relation between cGMP, 17-OH-CS, and "Yin Deficiency", which means that cGMP may form the basis of "Yang" here, and the "Yang" that cGMP represented actually was "deficient Yang" ascribed to the "Yin deficiency". The increased expression of 17-OH-CS before
HSCT means that the activated adrenocortical function may also be due to hyperactivation of "deficient Yang". The extremely low TT3 and FT3 in SAA before HSCT and their negative correlation with "Yang deficiency" suggested "Yang deficiency" before HSCT. All these changes indicated that both "Yin" and "Yang" were deficient in SAA; the "Yin deficiency" or "Yang deficiency" syndrome was actually the manifestation of deviated deficiency based on "Yin and Yang Deficiency".

Owing to dysfunctional iron metabolism and excess transfusion, iron overload (IO) is one of AA's most encountered complications, even in newly diagnosed patients. ${ }^{27,28}$ Analogism is regarded as a major theoretical construction tool of TCM, which has an important role in 


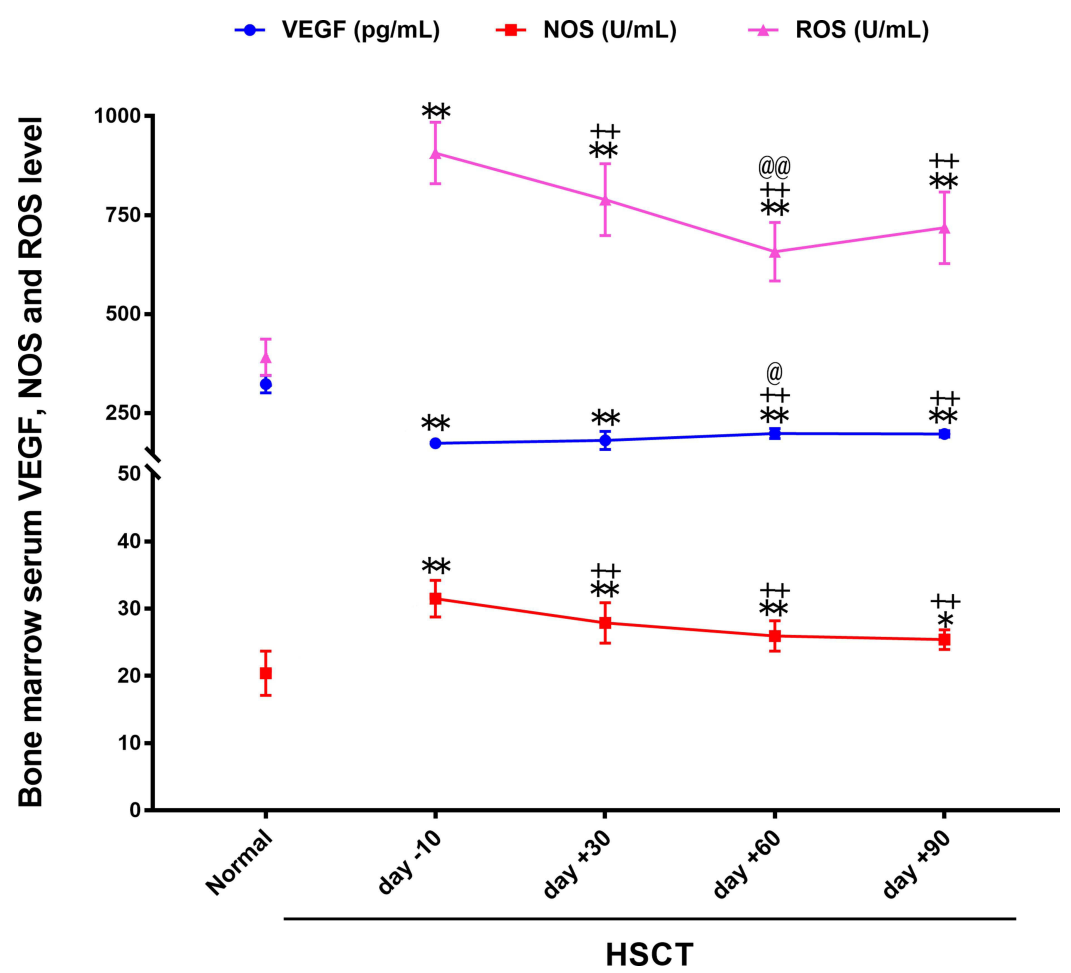

Figure 7 Changes of bone marrow VEGF, NOS, and ROS during HSCT process. The marrow serum level of VEGF, NOS, and ROS were detected. Data are presented as mean $\pm \mathrm{SD} ; * P<0.05, * * P<0.01$ (as compared with the normal population); ${ }^{++} P<0.01$ (as compared with $-10 \mathrm{~d}$ ); ${ }^{@} P<0.05$, and $@ @ P<0.01$ (as compared with $+7 \mathrm{~d}$ ).

concept design and theory systematization. In patients with heavy IO, hyperpigmentation occurs; some may even suffer from abdominal pain, which was similar to the patient with "Stasis" syndrome. Our previous study revealed a close relationship between IO and "Stasis" syndrome in chronic AA. Also, the iron chelation therapy contributed to the alleviation of "Stasis" syndrome and promoted the hematopoiesis, ${ }^{29,30}$ which is also in accordance with the TCM theory of "removing blood stasis for promoting tissue regeneration". Our result showed that nearly $61 \%$ of the patients were diagnosed with "blood stasis" syndrome before HSCT, and the stasis scoring increased after conditioning (until $+7 \mathrm{~d}$ ). However, after +14 day, the stasis score decreased, and $88.9 \%$ patients were diagnosed without stasis.

There was also a notable higher level of ferritin and LPI in AA patients, which suggested a higher iron load. Hepcidin is a major communicator between liver iron stores and the intestinal iron absorption and transport mechanisms that can negatively regulate the iron assimilation, and induce FPN endocytosis, phosphorylation, and catabolism. The expression of hepcidin was regulated by sTfR mediated HJV-BMP-SMAD pathway, ${ }^{31,32}$ and was upregulated in AA or myelodysplastic syndrome (MDS) with IO. ${ }^{33,34}$ Higher hepcidin, sTfR, and decreased FPN were also found in our cases. After HSCT, hepcidin started to significantly decrease 30 days after stem cell reinfusion, and FPN recovered to a normal level around +60day, while no obvious changes were observed on sTfR. In addition, the correlation analysis showed a strong positive relation of LPI, hepcidin, sTfR to "Yin Deficiency", while FPN was negatively related with "Yin deficiency" syndrome. We also found a positive correlation between hepcidin and sTfR, and a negative correlation between FPN and "stasis" syndrome. All these indicated that IO might contribute to the formation of "stasis", and that "Yin deficiency and blood stasis" may the tendentiousness syndrome in IO.

Besides the direct influence of iron overload to "Stasis", the impaired angiogenesis induced by oxygen free radical damage may also contribute to the stasis formation in AA patient. ${ }^{35}$ This study showed a significantly lower VEGF and extremely higher NOS and ROS in bone marrow from patients with SAA compared to the normal controls, and these indexes were corrected 30 to 90 days after HSCT. There was positive correlation of bone marrow NOS level to "Stasis" syndrome, and a negative correlation of VEGF to "Yin Deficiency" syndrome, which means that the oxygen free radical damage and impaired 

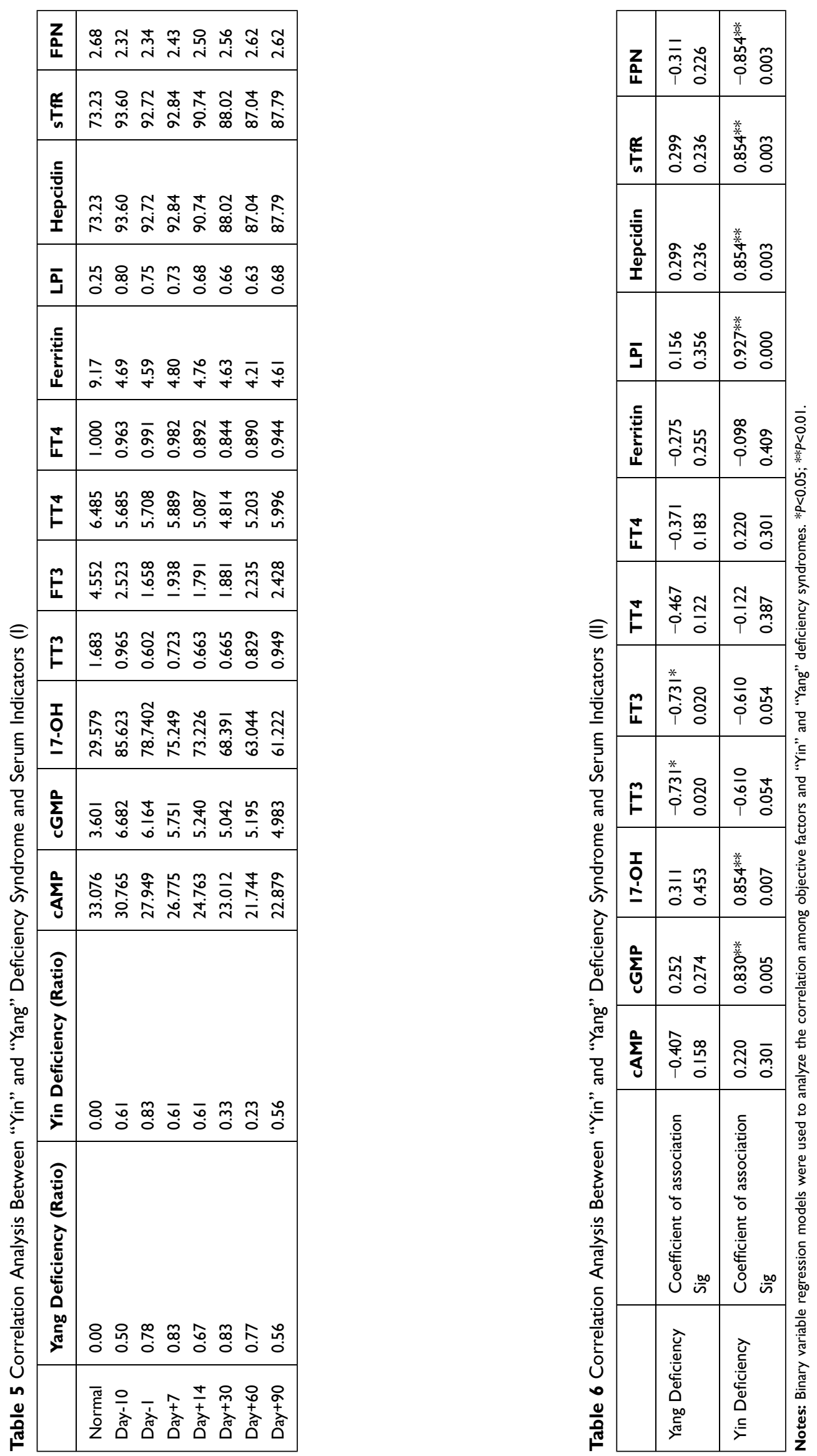

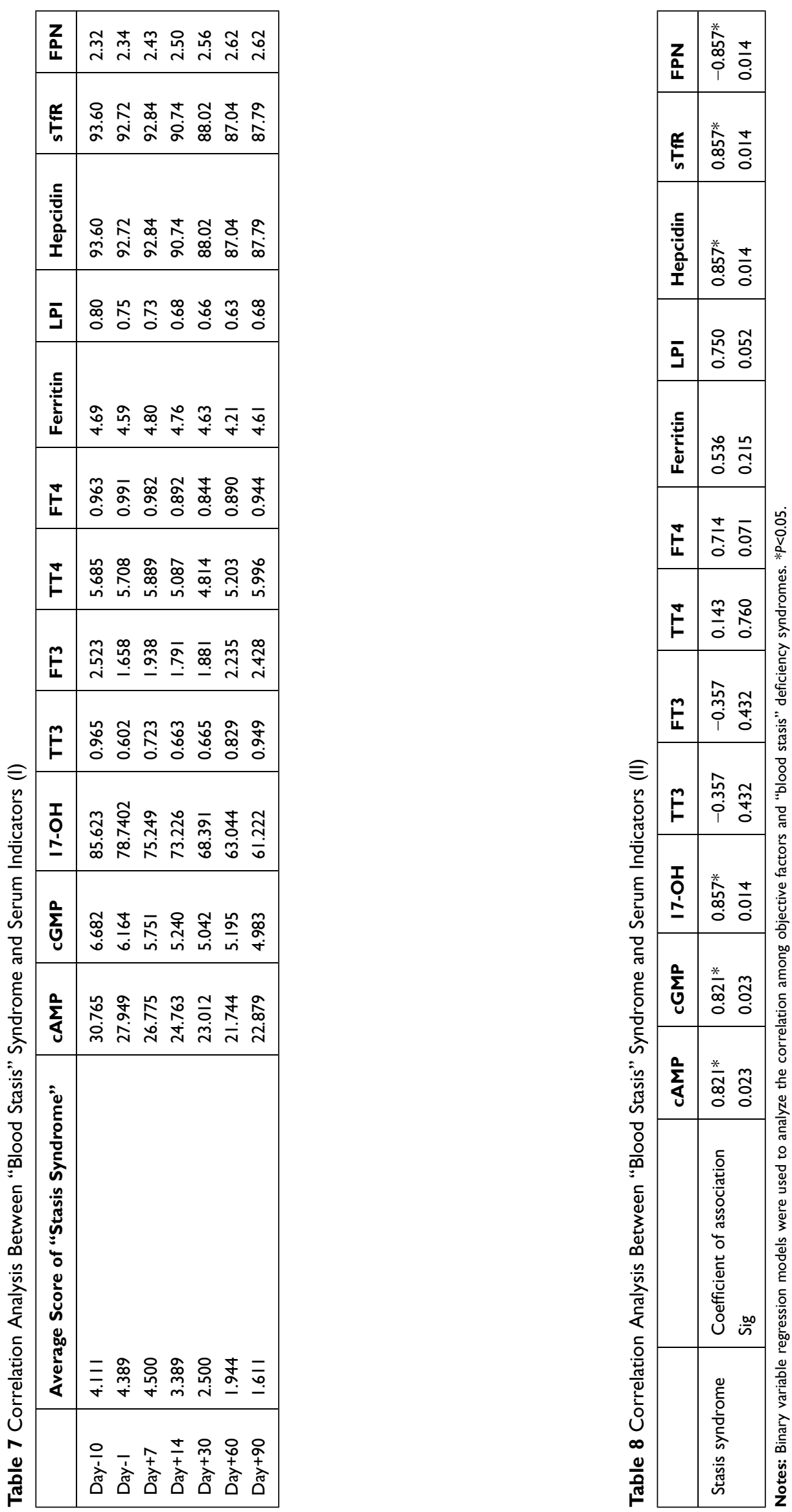
angiogenesis may also be the pathologic basis of "Yin deficiency and blood stasis" syndrome.

In conclusion, our study revealed the syndrome evolution pattern in AA patients undergoing HSCT, and found the possible basis of "Yin deficiency", "Yang deficiency", and "stasis" syndromes, which may promote the diagnosis and differentiation of the syndrome. For clinical practice, our results suggest it is necessary to take care of "Yin" during the whole stage of HSCT, as herbs with "hot" nature should be avoided in case of exhaustion of "Yin" regardless of their beneficial effect on hematopoiesis at the early stage, and "warm" herbs should be preferred instead. In addition, it is also necessary to understand "Stasis" in AA, where the abnormal iron metabolism may have a crucial role in the "blood stasis" syndrome formation, and therapeutic methods with blood-activating and stasis-resolving may be of considerable importance during the process of HSCT.

\section{Abbreviations}

AA, aplastic anemia; HSCT, hematopoietic stem cell transplantation; NOS, nitric oxide synthase; IST, immune suppression therapy; DFS, disease free survival; TCM, traditional Chinese medicine; CMDP, China Marrow Donor Program; Flu, fludarabine; ATG, anti-thymoglobulin antibody; CY, cyclophosphamide; MMF, mycophenolate mofetil; MTX, methotrexate; cAMP, cyclic adenosine monophosphate; cGMP, cyclic guanosine monophosphate; TT3, total triiodothyronine; FT3, free triiodothyronine; TT4, total tetraiodothyronine; FT4, free tetraiodothyronine; VEGF, vascular endothelial growth factor; ROS, reactive oxygen species; LPI, labile plasma iron; sTfR, soluble transferrin receptor; FPN, ferroportin; HPA, hypothalamic-pituitary-adrenal; IO, iron overload; MDS, myelodysplastic syndrome.

\section{Data Sharing Statement}

Additional data can be requested by contacting the corresponding author (wudijiong@zcmu.edu.cn) on the email address provided.

\section{Ethics Approval and Consent to Participate}

This study was approved by the ethical committee of First Affiliated Hospital of Zhejiang Chinese Medical University and registered with the Chinese Clinical Trials Registry, \# ChiCTR-ONC-1600803030. All the patients enrolled were gave informed consent and agreed to participate in the study. Informed consent was signed by all participants or their legal guardian (for patients under 18 years old). All procedures performed in studies involving human participants were in accordance with the ethical standards of the institutional and/or national research committee and with the 1964 Helsinki Declaration and its later amendments or comparable ethical standards.

\section{Funding}

This study was supported by the National Natural Science Foundation of China (No. 82174138), Research Project for Practice Development of National TCM Clinical Research Bases (No. JDZX2015109), Zhejiang Traditional Chinese Medicine Scientific Research Foundation (No. 2016 ZA069, 2020ZB085, and 2020ZB095), and China Association of Traditional Chinese Medicine Commissioned Project (No.202169-003).

\section{Disclosure}

The authors report no conflicts of interest in this work.

\section{References}

1. Young NS, Calado RT, Scheinberg P. Current concepts in the pathophysiology and treatment of aplastic anemia. Blood. 2006;108 (8):2509-2519. doi:10.1182/blood-2006-03-010777

2. Ye L, Zhang F, Kojima S. Current insights into the treatments of severe aplastic anemia in China. Int $J$ Hematol. 2020;112 (3):292-299. doi:10.1007/s12185-020-02955-1

3. Young NS, Kaufman DW. The epidemiology of acquired aplastic anemia. Haematologica. 2008;93(4):489-492. doi:10.3324/haematol. 12855

4. Ahmed P, Chaudhry QUN, Satti TM, et al. Epidemiology of aplastic anemia: a study of 1324 cases. Hematology. 2020;25(1):48-54. doi:10.1080/16078454.2019.1711344

5. Killick SB, Bown N, Cavenagh J, et al. Guidelines for the diagnosis and management of adult aplastic anaemia. Br J Haematol. 2016;172 (2):187-207. doi:10.1111/bjh.13853

6. Kamranzadeh Fumani H, Jalili M, Rad S, et al. Outcome of peripheral blood allogeneic hematopoietic stem cell transplantation as a treatment option in patients with severe aplastic anemia between 40 and 50 years. Hematol Oncol Stem Cell Ther. 2020;30111-30115. doi:10.1016/j.hemonc.2020.06.004

7. Xu ZL, Zhou M, Jia JS, et al. Immunosuppressive therapy versus haploidentical transplantation in adults with acquired severe aplastic anemia. Bone Marrow Transplant. 2019;54(8):1319-1326. doi:10.10 38/s41409-018-0410-3

8. Red Blood Cell Disease Group CSoHCMA. Chinese expert consensus on the diagnosis and treatment of aplastic anemia (2017). Zhonghua Xue Ye Xue Za Zhi. 2017;38:1-5. Chinese. doi:10.3760/ cma.j.issn.0253-2727.2017.01.001

9. Zhu N, Wu D, Ye B. The progress of traditional Chinese medicine in the treatment of aplastic anemia. J Transl Int Med. 2018;6 (4):159-164. doi:10.2478/jtim-2018-0031

10. Wu D, Shen Y, Ye B, et al. Efficacy and advantages of modified traditional Chinese medicine treatments based on "kidney reinforcing" for chronic aplastic anemia: a randomized controlled clinical trial. J Tradit Chin Med. 2016;36(4):434-443. doi:10.1016/S02546272(16)30059-0 
11. Ma R. Treatment of bone marrow failure syndrome with integrated traditional and Western medicine. Chin J Integr Med. 2007;13 (2):85-88. doi:10.1007/s11655-007-0085-x

12. Zheng BR, Shen JP, Zhuang HF, et al. Treatment of severe aplastic anemia by immunosuppressor anti-lymphocyte globulin/anti-thymus globulin as the chief medicine in combination with Chinese drugs. Chin J Integr Med. 2009;15(2):145-148. doi:10.1007/s11655-009-0141-9

13. Ye BD, Zhang X, Shao KD, et al. Combined use of Chinese medicine with allogeneic hematopoietic stem cell transplantation for severe aplastic anemia patients. Chin J Integr Med. 2014;20(12):903-909. doi:10.1007/s11655-014-2026-9

14. Kuang AK. Preliminary observation on endocrine and immune functions and concentration of cyclic nucleotides in plasma in "deficiency of yang" (author's transl). Zhonghua Nei Ke Za Zhi. 1979; 18:105-108. Chinese. PMID: 555897

15. Taylor MK, Hernandez LM, Kviatkovsky SA, et al. The "yin and yang" of the adrenal and gonadal systems in elite military men. Stress. 2017;20(3):258-264. doi:10.1080/10253890.2017.1333594

16. Yu W, Zhao H, Zong X, et al. The effects of Radix Astragali water abstract on energy metabolism in rat yang-deficiency cold syndrome model through PPAR signaling pathway. Evid Based Complement Alternat Med. 2018;2018:9194362. doi:10.1155/2018/9194362

17. Wang Q, Ren XJ, Yao SL, et al. Clinical observation on the endocrinal and immune functions in subjects with yin-deficiency constitution. Chin J Integr Med. 2010;16(1):28-32. doi:10.1007/ s11655-010-0028-9

18. Camitta BM. Pathogenesis and treatment of aplastic anemia. Rinsho Ketsueki. 1984;25:459-469.

19. Wu D, Ye B, Ji C, et al. Research status of clinical practice guidelines for aplastic anemia and amendment and thinking of TCM guidelines. $J$ Tradit Chin Med. 2014;55(3):274-278. doi:10.1016/S0254-6272(14) 60090-X

20. Wu D, Hu Z, Shen Y, et al. Approach of staging evidences of acute aplastic anemia. China J Tradit Chin Med Pharm. 2010;25:1099-1101.

21. Castro A, Jerez MJ, Gil C, et al. Cyclic nucleotide phosphodiesterases and their role in immunomodulatory responses: advances in the development of specific phosphodiesterase inhibitors. Med Res Rev. 2005;25(2):229-244. doi:10.1002/med.20020

22. Zeng Y, Li T, Zhang X, et al. Effects of Haima Duobian pill in a rat model of kidney yang deficiency syndrome. Evid Based Complement Alternat Med. 2021;2021:6696234. doi:10.1155/2021/6696234

23. Zhang L, Lang J, Jin L, et al. Effect of Hirsutella sinensis fungus on the hypothalamic-pituitary-adrenal axis in Lewis rats with kidney-yang deficiency syndrome. Evid Based Complement Alternat Med. 2020;2020:5952612.

24. Li GH, Wang QL, Liu FQ. [Experimental study of warming and recuperating kidney yang by you-gui-yin]. Zhong Xi Yi Jie $\mathrm{He} \mathrm{Za}$ Zhi. 1990;10:547-548, 518. Chinese. PMID: 2176578
25. Chen J, Feng G. Effects of the warming box-moxibustion on the symptom and the ratio of serum cAMP/cGMP in the subjects with Yang Deficiency Constitution. JJ Tradit Chin Med Univ Hunan. 2016;36:64-67.

26. Ji B, Li YY, Yang WJ, et al. Jinkui Shenqi Pills Ameliorate asthma with "Kidney Yang Deficiency" by enhancing the function of the hypothalamic-pituitary-adrenal axis to regulate $\mathrm{T}$ helper $1 / 2 \mathrm{imbal}$ ance. Evid Based Complement Alternat Med. 2018;2018:7253240. doi:10.1155/2018/7253240

27. Messa E, Biale L, Castiglione A, et al. Erythroid response during iron chelation therapy in a cohort of patients affected by hematologic malignancies and aplastic anemia with transfusion requirement and iron overload: a FISM Italian multicenter retrospective study. Leuk Lymphoma. 2017;58(11):2752-2754. doi:10.1080/10428194.2017. 1312385

28. Jin P, Wang J, Li X, et al. Evolution of iron burden in acquired aplastic anemia: a cohort study of more than 3-year follow-up. Int J Hematol. 2015;101(1):13-22. doi:10.1007/s12185-014-1708-6

29. Wu D, Luo Y, Liu W, et al. Correlation of iron overload and the manifestation of "Blood Stasis Syndrome" in chronic "Suilao" Patient: a single-center clinical study. J Zhejiang Chin Med Univ. 2016;40:265-269.

30. Wu D, Ye B, Luo Y, et al. Effects of deferoxamine on 42 patients with blood diseases and blood transfusion related iron overload. J Pract Med. 2013;29:142-144.

31. Schwartz AJ, Das NK, Ramakrishnan SK, et al. Hepatic hepcidin/ intestinal HIF-2alpha axis maintains iron absorption during iron deficiency and overload. J Clin Invest. 2019;129(1):336-348. doi:10. 1172/JCI122359

32. Wu D, Wen X, Liu W, et al. Comparison of the effects of deferasirox, deferoxamine, and combination of deferasirox and deferoxamine on an aplastic anemia mouse model complicated with iron overload. Drug Des Devel Ther. 2018;12:1081-1091. doi:10.2147/DDDT. S161086

33. Gattermann N. Iron overload in myelodysplastic syndromes (MDS). Int J Hematol. 2018;107(1):55-63. doi:10.1007/s12185-017-2367-1

34. Dijiong W, Xiaowen W, Linlong X, et al. Iron chelation effect of curcumin and baicalein on aplastic anemia mouse model with iron overload. Iran J Basic Med Sci. 2019;22:660-668.

35. Wu DJ, Ye BD, Hu ZP, et al. Bone marrow angiogenesis in patients presenting with differential Chinese medicine syndrome: correlation with the clinico-pathological features of aplastic anemia. Chin J Integr Med. 2013;19(12):905-912. doi:10.1007/s11655-013-1652-y
Journal of Blood Medicine

\section{Publish your work in this journal}

The Journal of Blood Medicine is an international, peer-reviewed, open access, online journal publishing laboratory, experimental and clinical aspects of all aspect pertaining to blood based medicine including but not limited to: Transfusion Medicine; Blood collection, Donor issues, Transmittable diseases, and Blood banking logistics; Immunohematology; Artificial and alternative blood based therapeutics; Hematology; Biotechnology/nanotechnology of blood related medicine; Legal aspects of blood medicine; Historical perspectives. The manuscript management system is completely online and includes a very quick and fair peer-review system. Visit http://www.dovepress.com/testimonials.php to read real quotes from published authors. 